\title{
Место «спортивной фразеологии» в составе общего фразеологического фонда современного русского языка
}

\author{
А. В. САВЧЕНКО \\ Department of Slavic Languages and Literatures, National Chengchi University \\ No. 64, Sec. 2, Zhinan Rd., 116, Wenshan District, TW-11605 Taipei City \\ E-mail: savchenko75@mail.ru
}

(Received: 29 March 2015; accepted: 17 June 2015)

\begin{abstract}
This paper touches upon the description of the phraseological units which are currently used in the sphere of sports in present-day Russian. Such units have their origin both in sports slang and in mass media language. On the other hand, such units have not only a high level of expressivity but nowadays they are often used as picturesque and metaphoric means in other discourses, e.g. political, social, economic, and in everyday communication. This type of sports idioms now constitutes a special section in the general phraseological base of Russian.
\end{abstract}

Keywords: phraseology, Russian, sports language, idioms, determinologization, neology

В последние десятилетия (на рубеже XX - начале XXI века) происходит активное развитие как лексического состава русского языка в целом, так и его фразеологического фонда. Во фразеологическом составе языка наблюдаются изменения, связанные, в частности, с расширением фразеологического фонда за счет ставших актуальными, популярными сфер употребления языка.

Традиционно считается, что прежде чем стать фразеологизмом, словосочетание должно пройти достаточно длительный путь «идиоматизации». Как отмечал Б. А. Ларин, «,неразложимые словосочетания“ (идиомы, фразеологические сращения) явились в результате ряда деформаций словесного выражения мысли, когда-то вполне ясного, недвусмысленного и конкретного, отвечавшего нормам живого языка и по грамматическому строению, и по лексическому составу, и по семантическому содержанию. Семантическая слитность, целостность образуется раньше, скорее. Для „созревания“ грамматической неразложимости нужны века» (ЛАРин 1977: 137).

Вместе с тем, последние десятилетия отмечены резким ускорением темпа жизни, что во многом связано с политическими процессами в ряде стран Европы и мире в целом, стремительным развитием прогресса практически во всех сферах жизни и деятельности человека. Все это неизбежно находит свое отражение в языке. Можно заметить, что наиболее заметные процессы происходят в области лексики. В первую очередь, к этим процессам необходимо отнести неологизацию и интернационализацию лексического состава языка. В то же время возникает потребность создания ярких образных выражений, с помощью которых можно было бы, с одной стороны, обозначить 
какое-либо (новое) явление, реалию, дать емкое определение, характеристику, а с другой стороны, - выделить такую единицу в тексте, сделать фразу заметной, броской, заставить обратить внимание на сообщаемое с помощью различных стилистических эффектов: необычности образа, экспрессии, «языкового колорита». Все это ведет к изменениям не только в лексическом, но и фразеологическом составе языка: в настоящий момент мы можем говорить об активных процессах неологизации во фразеофонде русского языка (подробнее об этом см., в частности, МокиЕнко 2002, МоКИЕнко 2003).

Непосредственно говоря об источниках фразеологических единиц (далее - ФЕ), можно отметить, что если раньше главную роль в возникновении и в дальнейшем употреблении фразеологизмов традиционно играла устная речь, устное народное творчество (так или иначе можно предположить, что многие фразеологизмы имеют фольклорные корни: они зарождались именно в народно-разговорной речи, устном творчестве народа) и художественная литература, то в последние десятилетия значительную роль в формировании фразеологического фонда, наряду с различными традиционными средствами массовой информации (радио, телевидение), играет Интернет.

Как представляется, сферы жизнедеятельности человека, вызывающие наибольший интерес, привлекающие к себе в обществе пристальное внимание, те сферы, которые оказывают воздействие на аудиторию и вызывают ее ответную реакцию, особенно остро нуждаются в ярких средствах создания образности и экспрессии. К таким наиболее актуальным областям традиционно относятся сферы политики и экономики.

Нельзя хотя бы коротко не упомянуть также о значительной роли и влиянии на повседневный язык военной сферы и языка пропаганды. Достаточно вспомнить такие расхожие выражения определенной исторической эпохи как гонка вооружений, поджигатели войны, а также выражения, рожденные под влиянием «военной метафоры», например, битва за урожай, сражения на полях страны (о сборе урожая) и многие другие.

Начиная приблизительно с середины 80-х гг. XX века, в языковой обиход вошло достаточно большое количество выражений (включая клише и штампы, идеологемы и так называемые «советизмы», о которых нужно говорить отдельно, см., например, МокиЕнко-Никитина 2005), в том числе имеющих терминологический и фразеологический характер, которые относятся к названным выше областям. При этом нередко можно наблюдать случаи, когда слово, понятие (т. е. термин) или определенное устойчивое сочетание (т. е. ФЕ) выходит за рамки узко-специфического значения и приобретает более широкое, по сути, фразеологизированное, метафорическое значение.

Наряду с политикой и экономикой еще одной традиционно популярной областью является спорт. Спорт сегодня продолжает активно развиваться, превращаясь из профессиональной спортивной деятельности в коммерческий продукт и разновидность шоу-бизнеса. Все эти ведущие области (политика экономика и финансы - спорт) имеют очевидные сходные черты. В спорте можно обнаружить явления, во многом аналогичные, а подчас и напрямую 
обусловленные изменениями в сфере политики и экономики. В последнее время мы наблюдаем все более тесное «сращение» политики и спорта, что находит свое отражение и подтверждение в расхожей метафоре «спорт - это политика» (и даже «политика - это спорт»).

Таким образом, можно констатировать, что главной характеризующей сферу спорта чертой последнего времени является то, что за последние пару десятилетий она окончательно вышла за чисто спортивные, соревновательные рамки. Сегодня эта сфера включает в себя основные черты общего дискурса, в частности, политику, экономику и бизнес, медицину и психологию, рекламную индустрию и индустрию развлечений и др.

Следует особо отметить тесную связь спортивной и военной сфер: их близость (а в некоторых случаях, фактически, тождество) во многом обусловливается общим «состязательно силовым» характером этих сфер: победит тот, кто сильнее, умнее, хитрее. Во многом схожи данные сферы и по стратегии и принципу целого ряда тактико-технических действий на поле военного сражения и игровом поле.

Другая особенность сферы спорта заключается в зрелищности практически всех наиболее популярных видов спорта, при этом «пальма первенства» в основном принадлежит командным видам спорта. Благодаря этому спорт во многом пересекается с разными сторонами искусства: театром, кино, музыкой, живописью.

Тесная связь всех этих вышеперечисленных сфер с миром спорта проявляется, в частности, в широком использовании устойчивых выражений, метафор, свойственных какой-либо из этих сфер, в определенном спортивном контексте, например, нанести поражение, подносчик снарядов (в спорте: 'игрок, отдающий передачи'), быть в обойме (в спорте: 'быть в основном составе команды'), попасть в обойму (в спорте: 'оказаться в основном составе команды'), выпасть из обоймы (в спорте: 'перестать попадать в основной состав команды'), психология победителя, как по нотам, под занавес, играть с листа, смотреть кино ('во время игры просматривать спорный момент по видеозаписи') и др.

В настоящее время в сфере спорта наблюдаются процессы активной фразеологизации. Многие выражения и относительно устойчивые обороты идиоматизируются, намечается переход от окказионального к регулярному их употреблению в определенном значении и контексте, наблюдается тенденция к закреплению их компонентного состава. Иногда такие выражения уже, по сути, возникают «готовыми» ФЕ: удачно придуманный журналистами эпитет, сравнение, образное выражение, точно и емко характеризующее определенное явление или реалию, в некоторых случаях становится расхожим оборотом с высокой степенью устойчивости значения и компонентного состава. То же самое можно сказать о «крылатых фразах», когда благодаря СМИ тиражируется и становится общеупотребительным какое-либо «острое», неординарное высказывание «людей спорта», в первую очередь, спортсменов и тренеров. 
Возвращаясь к степени популярности определенного вида спорта и его роли в обогащении фразеологического фонда, сошлемся на исследование польского филолога В. Хлебды, который в этой связи справедливо отмечает: «Наибольший вклад в общую фразеологию внесли игровые виды спорта. Ядро фразеологического „поля спортивности“ образовали 3 игры с мячом: футбол, баскетбол и волейбол, а также отчасти легкая атлетика, бокс и теннис» (ХлЕБдА 2005: 91). К этому списку, по нашим наблюдениям, можно также добавить шахматы, бильярд и фигурное катание.

Выделяем основные источники ФЕ, связанных со спортивной сферой:

1. Профессиональная среда спортсменов: профессиональный разговорный (жаргонный) устойчивый оборот $\rightarrow$ ФЕ. Спортивный жаргон в настоящее время является одним из популярных и, можно сказать, даже модных источников новых для «общего фразеоязыка» ФЕ, например, бокса: отправить искать пятый угол, быстрый бой, корявый боксер, [быть, находиться] в ауте, стеклянная челюсть; футбола: сгонять договорняк, отправить игрока в буфет, посадить игрока на вилье, взять в коробочку, посадить игру на свисток, играть от ножа, тещина нога; баскетбола: играть на столба, забить кола, забросить от доски, поставить горшок, слепой заслон; шахмат: вырубить хвост, бешеная фигура, детский мат, дурачкий мат, домашняя заготовка, на флажке; бильярда: зачистить стол, сыграть воздухом, забить дурака, «тихий» свояк, фуксовый игрок; хоккея: выставить илагбаум, накидать полную авоську (кошелку), посадить на виль, смотреть кино, гол со скамейки, прокатиться на пистолете; тенниса: взять большой шилем, ударить лопатой, [мяч] на «лопату», повесить «соплю» (настольный теннис), первая ракетка [мира]; автоспорта: тещин дворик, тещин язык; велоспорта: висеть на колесе, быть при ноге; биатлона: на десять часов ушло, на полшестого, отстрелять на ноль, а также многие другие подобные единицы из профессионализмов разных видов спорта (из менее известных и популярных видов спорта все же приведем пару примеров из языка спортсменовдельтапланеристов: чайное поле, махнуть на топлесс).

Если раньше такого рода лексические единицы использовались фактически исключительно в профессиональной спортивной среде и практически не встречались в языке спортивной журналистики, то в последнее время их можно услышать не только в речи профессиональных спортсменов, но и тех, кто занимается освещением различных спортивных событий, в первую очередь, к ним относятся комментаторы и спортивные журналисты. С одной стороны, это создает в статье или репортаже необходимое эмоциональное напряжение, привносит в него дополнительную экспрессию, придает языку колорит и своеобразный «эффект присутствия» внутри профессионального спортивного сообщества. С другой стороны, сегодня многие комментаторы сами бывшие спортсмены, и спортивные жаргонизмы они используют по привычке. Отдельные жаргонизмы, помимо образности и экспрессии, способны отражать некоторые нюансы игры, которые затруднительно описать или выразить обычными языковыми средствами.

Studia Slavica Hung. 60, 2015 
В целом, говоря о роли жаргона в пополнении фразеологического фонда, сошлемся на мнение В. М. Мокиенко, считающего, что «жаргон (resp. арго, сленг) со всеми его „дифференциалами“ в этом „Drang nach Substandart“ играет доминирующую роль, хотя интенсивно и влияние других сфер живой речи (разговорно-просторечные элементы, диалектизмы, профессионализмы)» (МокиЕнко 2002: 67, МокИЕнко 2003: XVI).

2. Устойчивые выражения (в т. ч. штампы), активно использующиеся СМИ $\rightarrow$ ФЕ: нанести поражение, подобрать ключи к воротам, распечатать ворота, гвоздь тура, группа смерти, команда-лифт, бизнес-матч, спорт номер один, король спорта, королева спорта, королева автоспорта, кудесники мяча, люди в черном, рыцарь пяти качеств, рыцарь двух качеств, болезнь чужсого поля, бумажный фаворит, бумажный аутсайдер, весенний футбол, двенадиатый игрок, снежный снайпер, тренерская дуэль, футбольный карлик, английская неделя, очковый багаж, очковая болезнь, турнирное болото и т. д. Журналистские шаблоны и штампы в языке СМИ - явление достаточно распространенное и хорошо описанное в лингвистической литературе. Такого рода «клишированные выражения» характерны практически для всех освещаемых журналистикой областей. Наряду с относительно устойчивыми выражениями, которые из-за отсутствия у них образности, их слабой или «стертой» экспрессивности, имеют, скорее, именно характер клише или штампа, в языке спортивной прессы, устного спортивного репортажа существует целый ряд образных, экспрессивных фразеологизированных оборотов, возникших и/или распространившихся благодаря спортивным журналистам. Как правило, такой удачно созданный образ или экспрессивное выражение постепенно входит в языковой обиход и имеет большие шансы стать ФЕ. Особенно распространенными устойчивыми единицами фразеологического характера в языке спортивной журналистики можно считать перифразы типа король спорта 'футбол', рыщарь пяти качеств 'пятиборец', рыщарь двух качеств 'биатлонист', страж ворот 'вратарь', железная игра 'тяжелая атлетика', ледовый бал 'выступления фигуристов', ледовый боещ, ледовый рыщарь 'хоккеист', ледовая баталия 'хоккейный матч', лучшая подруга вратаря 'штанга', пятнистый друг 'футбольный мяч', черная таблетка 'шайба', ведро без дна 'баскетбольная корзина', тряпочная авиация 'дельтапланеризм', современный Икар 'дельтапланерист’, двенадцатый игрок 'болельщики в футболе' и др.

3. Интертекстемы - прецедентные тексты, прецедентные ситуации и т. п., «крылатика» в широком смысле: академики с тросточкой, игрок по фамилии Плеймейкер, команда тренерской мысли, прыжок для газеты «Пионерская правда», рука Бога, изюмный игрок, искренний футбол, ледовая дружина, отработанный материал, полотерский номер, порядок бьет класс, ББББ (бил, бью, буду бить), сексуальный футбол, парковать автобус в штрафной и др. Такие «фразеологизированные» единицы также рождаются, как правило, благодаря СМИ: чаще всего они имеют цитатный характер. Журналисты выдергивают из контекста и тиражируют емкие образные, ярко экспрессивные, 
нестандартные высказывания спортсменов и тренеров, в том числе и спортивных комментаторов (именно в этом заключается принципиальное отличие устойчивых выражений интертекстемного характера от журналистских клише и штампов: у единиц первой группы, как правило, имеется конкретный автор, а у вторых это, скорее, плод «коллективного творчества» журналистов; многие такие выражения имеют фактически интернациональный характер: группа смерти, золотой гол, золотой матч, мгновенная смерть, фэйр плей и т. п.). Сюда также можно отнести ставшие «крылатыми» благодаря использованию в текстах песен и других произведениях выражения типа: великолепная пятерка [и вратарь], ледовая дружина и др. При возникновении «авторских» ФЕ оригинальный текст (сказанная спортсменом или тренером фраза) иногда подвергается дальнейшей трансформации в зависимости от цели и интерпретации использующего цитату журналиста.

4. Спортивный термин $\rightarrow$ ФЕ (детерминологизация): войти в клинч, выбросить полотенце, держать удар, играть на чужом поле, прижать к канатам, оказаться в дамках, выйти в дамки, отправить в нокаут, попасть в ичейтнот, устроить сюрпляс, игра на опережение, скамейка итрафников, удар ниже пояса, финишный спурт, желтая майка лидера, желтая карточка, красная карточка, марафонский бег, обязательная программа, произвольная программа и др. Благодаря емкости, потенциальной контекстуальной экспрессивности и образности целый ряд выражений-терминов уже вышел (или находится в процессе перехода от чисто термина к «фразеологизированной единице») за сугубо терминологические рамки и приобретает статус ФЕ, где на первый план выходят именно экспрессивность и образность. При этом в языке спорта они, как правило, продолжают выполнять чисто терминологическую функцию, а в общий фразеофонд входят в качестве уже готовых или потенциальных ФЕ. Таким образом, «источниками возникновения новых ФЕ в современном русском языке являются терминологические системы, в первую очередь спортивная и военная, литературные произведения, в частности песни, и образные выражения разговорной речи» (МАлински 1992: 76).

Возможен и обратный процесс - «терминологизация» выражения, обозначающего какое-либо понятие, реалию и первоначально употреблявшегося в качестве профессионализма (жаргонизма) или как «медийный штамп». Со временем некоторые из таких оборотов приобретают характер термина. За ними закрепляется определенное значение, они используются в официальных формулировках положений правил и т. п.: золотой гол, серебряный гол решающий, победный гол в матче (правило золотого гола, правило серебряного гола), мгновенная смерть - выигрывает команда, первой забившая гол в дополнительное время (правило мгновенной смерти), сухой лист - тип удара в футболе и др.

5. ФЕ из общего фразеологического фонда $\rightarrow$ ФЕ в спортивном контексте или со спортивным значением: быть в обойме, [выложить] как на блюдечке, выпасть из обоймыл, закатать в асфальт, порвать на британский флаг, сделать клоуна из кого-л., тасовать колоду, [разыграть] как по нотам, 
мальчики для битья, [играть] с листа, рабочая лошадка, холодный душ 'неожиданно пропущенный гол', с шашками наголо, шапкозакидательское настроение (от ФЕ закидать шапками) и др. Целый ряд ФЕ, традиционно относящихся к общему фразеофонду, широко используется в «языке спорта», при этом такие единицы могут приобретать более четко выраженное спортивное значение или дополнительные оттенки к основному значению ФЕ: $n o$ ставить победную точку 'забить победный гол', оставить не у дел игрока 'обыграть игрока, часто забив при этом гол', держать на голодном пайке 'крайне редко или совсем не отдавать пас игроку в течение матча', yстроить [показательную] порку кому-л. 'выиграть с крупным счетом' и др.

Продуктивной основой для создания новых ФЕ с уже чисто спортивным значением становятся и некоторые фразеологические модели. Наиболее яркий пример - ФЕ скрестить шпаги, которая в чисто спортивном контексте получила значение 'встретиться в спортивном поединке' и по модели которой созданы, например, выражения скрестить бутсы, весла, клюшки, перчатки, ракетки. Такой же продуктивной фразеологической моделью можно считать оборот повесить что-л. на гвоздь. Это достаточно древняя модель, широко распространенная в славянских и европейских языках (об этом подробнее см. БМС 2007). В спортивном обиходе модель получила дальнейшее развитие путем подстановки на позицию прямого дополнения - наименование конкретного спортивного атрибута (как правило, это основной элемент экипировки спортсмена), характерного для данного вида спорта: повесить бутсы, клюшку, лыжи, перчатки, ракетку, свисток... на гвоздь. Зафиксирована даже не очень удачная с точки зрения логики ФЕ повесить весла на гвоздb (в обычной жизни весла обычно не вешают, а ставят).

Итак, можно констатировать, что для языка сферы спорта в настоящее время характерно активное использование существующих в профессиональной речи спортсменов и спортивных журналистов выражений, а также создание новых ярких, образных, экспрессивных оборотов, отражающих разные стороны и реалии спортивной жизни. Вместе с тем, в сфере спорта активно используется целый ряд ФЕ, характерных для общего фразеофонда. В некоторых случаях единицы общей фразеологии получают специфическое спортивное значение.

Следует особо отметить, что благодаря своей «универсальности», т. е. схожести чисто спортивного значения и многих явлений и реалий повседневной жизни, контекстов употребления, - с одной стороны, и яркой образности, высокой степени эмоциональности и при этом лаконичности, емкости, понятности образа, «кумулятивности» его значения - с другой, спортивные ФЕ могут использоваться и вне сферы спорта. В этой связи важно подчеркнуть тот факт, что многие выражения, пришедшие из мира спорта, стали адекватной заменой послевоенному «милитаристическому» дискурсу в языке средств массовой информации. Результатом такой «подмены» стало заметное снижение «риторики агрессии», уровня напряженности, агрессивных настроений в политике и международных отношениях. Э. Лассан объясняет замену военных 
метафор спортивными так: «метафора идеологической борьбы, конфронтации двух лагерей в мире с разными общественными устройствами, составлявшая основу политических текстов советского периода (будь то внешнеполитические отношения или отношения внутри страны в период 30-40-х годов) сменилась в начале 90-х прошлого века, после провозглашенной М. С. Горбачевым „деидеологизации“ политики, иными метафорами - спорта, шоу...» (ЛАССАН 2010: 25). Таким образом, спортивные метафоры, в отличие от чисто военных, «милитаристических», способны не менее ярко и образно выразить сходные понятия, но гораздо мягче, «политкорректнее» (об этом также см. ХлЕБДА 2005). Многие выражения, использующиеся в сфере спорта как термины, профессионализмы или относительно устойчивые разговорные обороты, достаточно легко и вполне адекватно, при этом не менее образно, но значительно «миролюбивее», заменяют агрессивные по своему характеру «военизированные» метафоры. «Таким образом, метафора политической борьбы, войны двух лагерей, предполагающая и физическое устранение „врага“, сменилась менее „кровожадной“, однако достаточно близкой по духу метафорой спорта: прекращение войны на время Олимпийских игр в античности можно рассматривать как сублимацию потребности в уничтожении другого (агрессии) в потребность противоборства на спортивных состязаниях („Спорт - это имитация войны““ [Джордж ОруэлЛ])» (ЛАССАН 2013: 25).

Таким образом, подтверждается мысль Б. А. Ларина о том, что «на протяжении XIX-XX вв. можно наблюдать переход от вполне текучих („,свободных“) к устойчивым словосочетаниям, часть из которых, возможно, превратится со временем в идиомы. Переходные типы от простых выражений с прямым и конкретным значением к фразеологическим стереотипам возникают и сейчас [уже и в XXI в. - А. С.]» (ЛАРин 1977: 146). Анализ формирования и функционирования рассмотренных единиц также доказывает утверждение Б. А. Ларина о том, что «путь мысли от частного к общему, от конкретно-единичного к типично-обобщенному отражается в языке созданием метафорических, образно-иносказательных выражений, а дальше - отвлеченно-точных формул и условно-символических обозначений» (ЛАРин 1977: 146). Как раз подобные процессы характерны в наши дни для языка сферы спорта. Целый ряд словосочетаний, регулярно употребляющихся применительно к области спорта, проходит путь от окказионализма к устойчивости, от «свободного» к неразложимому: то, что Б. А. Ларин назвал «идиомой в зародыше».

В целом на данном этапе можно отметить то, что «спортивная фразеология» пока не имеет четко определенного характера и границ. Вероятно, можно говорить лишь о стадии зарождения непосредственно раздела спортивной фразеологии в рамках общей фразеологии. Как одно из свидетельств того, что многие единицы пока не являются ФЕ в классическом их понимании - неустоявшийся компонентный состав, большая вариативность (быть) оказаться в дамках, закрутить/закружить карамболь пустить/поймать бабочку, сохранить/оставить ворота сухими и т. п.) и «размытость» значения некоторых таких лексических единиц. 
Отсутствие паспортизации (т. е. крайне слабая фиксация) единиц собственно спортивной фразеологии (в отличие от «отспортивных»: ФЕ, перешедших из сферы спорта в общий фразеофонд или ставших ФЕ непосредственно в «общем» языке) современными словарями ставят задачу дальнейшего исследования данной темы, создания более детальной классификации и дефиниции рассматриваемых лексических единиц в будущем.

\section{Литература}

БМС 2007 = БИРИХ А. К., МокИЕНКО В. М., СТЕПАНОВА Л. И. Русская фразеология. Историко-этимологический словарь. Москва, 2007.

ЛАРИН 1977 = ЛАРИН Б. А. Очерки по фразеологии (о систематизации и методах исследования фразеологических материалов). В кн.: ЛАРин Б. А. История русского языка и общее языкознание. Москва, 1977. 125-149.

ЛАССАН $2010=$ ЛАССАН Э. О формах существования концептуальных метафор как индикаторах силы и бессилия общества. Политическая лингвистика 2010/1: 2433.

МАлинСКИ 1992 = МАлинСКИ Т. Возникновение новых фразеологических единиц. Rusistika (Berlin) 1992/2: 67-76.

МокиЕнко 2002 = МокиЕнко В. М. Проблемы европейской фразеологической неологики. In: Stowo. Text. Czas VI. Nowa frazeologia w nowej Europie. Materiały VI Międzynarodowej Konferencji Naukowej (Szczecin, 6-7 września 2001 r. Greifswald, 8-9 września 2001 r.). Szczecin-Greifswald, 2002. 63-76.

МокиЕнко 2003 = Мокиенко В. М. Новая русская фразеология (60-90-егоды). Материалы к словарю. Opole, 2003.

МоКИЕНКО-НикИтинА 2000 = МокиЕНко В. М., НикитинА Т. Г. Большой словарь русского жаргона. Санкт-Петербург, 2000.

МокиЕнко-НикитинА 2005 = МокиЕнко В. М., НикитинА Т. Г. Толковый словарь языка Совдепии. Москва, 2005.

ХЛЕБДА 2005 = ХЛЕБДА В. Фразеология спортивного происхождения в сегодняшнем польском публичном дискурсе. In: Frazeologické štúdie IV. Bratislava, 2005. 87-93. 